\title{
DA RADIODIFUSÃO PARA O AUDIOVISUAL: CONTRIBUIÇÕES PARA A DEFINIÇÃO DE UM CONCEITO ABRANGENTE EM TEMPOS DE CONVERGÊNCIA MIDIÁTICA ${ }^{1}$
}

\section{FROM BROADCASTING TO AUDIOVISUAL: CONTRIBUTIONS TO THE DEFINITION OF A CONCEPT COMPREHENSIVE IN TIMES OF MEDIA CONVERGENCE}

\section{CARLO JOSÉ NAPOLITANO}

Pós-Doutor pelo Departamento de Direito do Estado, da Faculdade de Direito, da Universidade de São Paulo. Doutor em Sociologia pelo Programa de Pós-Graduação em Sociologia da Faculdade de Ciências e Letras, UNESP/Araraquara. Professor Associado da Universidade Estadual Paulista - UNESP, Departamento de Ciências Humanas e do Programa de Pós-Graduação em Comunicação, da Faculdade de Arquitetura, Artes e Comunicação, Bauru/SP, Livre-Docente em Direito à Comunicação, e-mail: carlo.napolitano@unesp.br.

FLÁVIA PIVA ALMEIDA LEITE

Professora Assistente Doutora da Universidade Estadual Paulista - UNESP, Departamento de Ciências Humanas de Bauru e do Programa de Pós-Graduação em Direito da UNESP - Franca. e-mail: flavia.leite@unesp.br

\footnotetext{
${ }^{1}$ As ideias centrais do artigo foram por um dos autores (Carlo José Napolitano) apresentadas no texto e publicadas no evento: " Contributos da Teoria Portuguesa para a definição do conceito de radiodifusão na legislação brasileira: ampliação da divulgação da cultura nacional dos serviços de audiovisual" - Trabalho apresentado no II Congresso Internacional sobre Culturas: Diálogos Brasil Portugal, 2016, Salvador. Diálogos Brasil- Portugal e publicados nos Anais do II Congresso Internacional sobre Culturas: UFBA, 2016, v. 1, p. 336-343.
} 


\section{FELIPE DE OLIVEIRA MATEUS}

Doutorando em Comunicação pelo PPGCom da FAAC/Unesp. Jornalista da Secretaria Executiva de Comunicação da Universidade Estadual de Campinas (Unicamp), graduado pela FAAC/UNESP, Mestre. E-mail: felipe.omateus@hotmail.com

\section{RESUMO}

Objetivo: Indicar contribuições teóricas de documentos jurídicos e do campo comunicacional, nacionais e estrangeiros, para a superação do conceito de radiodifusão e sua ampliação para o conceito de audiovisual em um ambiente de convergência midiática.

Metodologia: O presente trabalho lastreado em pesquisa bibliográfica e documental utiliza-se de método analítico-sistemático dedutivo objetivando demonstrar as questões e apontar as contribuições teóricas, jurídicas e do campo comunicacional, e de documentos nacionais e estrangeiros acerca da temática.

Resultados: A teoria e a legislação portuguesa, acrescidas das diretivas europeias sobre o audiovisual, podem contribuir para a definição de um conceito mais amplo de radiodifusão na legislação brasileira, ampliando-se o conceito para além do espectro eletromagnético, abarcando todo e qualquer serviço de comunicação social audiovisual, independente do suporte tecnológico.

Contribuições: Uma definição e clarificação conceitual, necessária em tempos de convergência midiática e internacionalização dos mercados; fatos que impactam a regulação local, alterando a configuração do direito interno, em regra e historicamente pautado pelos aspectos arquitetônicos e estruturais de limitação do espectro eletromagnético, que caminha para uma regulação voltada ao conteúdo.

Palavras-chave: Constituição; televisão; radiodifusão; convergência midiática; comunicação social.

\section{ABSTRACT}

Objective: To indicate theoretical contributions of legal documents and of the communication field, national and foreign, to overcome the concept of broadcasting and its expansion to the concept of audiovisual in an environment of media convergence. 
Methodology: The present paper backed by bibliographic and documentary research uses a deductive analytical-systematic method in order to demonstrate the issues and point out the theoretical, legal and communicational contributions, and of national and foreign documents on the subject.

Results: The theory and Portuguese legislation, in addition to the European directives on audiovisual, can contribute to the definition of a broader concept of broadcasting in Brazilian legislation, expanding the concept beyond the electromagnetic spectrum, encompassing any and all broadcasting services, audiovisual media, regardless of technological support.

Contributions: A definition and a conceptual clarification, necessary in times of media convergence and internationalization of markets; facts that impact local regulation, changing the configuration of domestic law, as a rule and historically guided by architectural and structural aspects of limitation of the electromagnetic spectrum, which moves towards regulation geared to content.

Keywords: Constitution; television; broadcasting; media convergence; social communication.

\section{INTRODUÇÃO}

O texto da Constituição de 1988 , ao abordar a temática da comunicação social, em especial, da comunicação social televisiva e radiofônica, utiliza diversas expressões, tais como: veículo de comunicação social, meios de comunicação social, emissoras de rádio e televisão, empresa de radiodifusão de sons e de imagens, meios de comunicação social eletrônica, radiodifusão e televisão e serviço de radiodifusão. A falta de uma definição clara e precisa sobre os termos pode gerar insegurança jurídica e tratamento não isonômico para as empresas que atuam no setor audiovisual.

Neste sentido o presente trabalho almeja apontar as contribuições teóricas, jurídicas e do campo comunicacional, e de documentos nacionais e estrangeiros acerca da temática, no intuito de alargar o conceito de televisão para todo e qualquer tipo de produção audiovisual, independentemente do meio ou do tipo de transporte do conteúdo, inclusive para os serviços on demand e via streaming. 
O presente trabalho, lastreado em pesquisa bibliográfica e documental, utiliza-se de método analítico-sistemático dedutivo objetivando demonstrar as questões acima mencionadas e, para tanto, está assim estruturado: apresentação das legislações brasileira e portuguesa no que tange ao termo radiodifusão; indicação das contribuições da teoria jurídica portuguesa em relação à definição de um conceito amplo de radiodifusão; aportes de diretiva europeia acerca dos serviços de audiovisual; apresentação de contribuição da teoria e de documentos jurídicos brasileiros para uma definição do termo audiovisual; abordagens sobre o direito e a convergência, em uma perspectiva do campo comunicacional e, por fim, apresentação de considerações finais, concluindo que a regulação jurídica constitucional, após a Emenda Constitucional ํ․ 36/2002, permite a regulação do setor da comunicação social amparada no conteúdo transmitido, aplicando-se todas as regulações previstas no texto constitucional para as empresas que atuam no setor, independentemente da tecnologia utilizada.

\section{DA RADIODIFUSÃO NAS LEGISLAÇÕES BRASILEIRA E PORTUGUESA}

A Constituição brasileira por oito vezes trata expressamente da radiodifusão, de diversificadas maneiras. No artigo 21 , inciso XII, alínea a, ao tratar das competências administrativas da União, dispõe que uma dessas atividades é a exploração dos serviços de "radiodifusão sonora, e de sons e imagens". No artigo 22, inciso $V$, está disposto que compete privativamente à União legislar sobre "radiodifusão". O artigo 48, inciso XII, atribui competência ao Congresso Nacional para tratar dos assuntos referentes à "radiodifusão". O artigo 139, inciso III, trata das restrições de direitos em Estado de Sítio, prevendo que uma dessas hipóteses é a restrição à "radiodifusão e televisão". O artigo 155 , inciso X, alínea d, dispõe que o imposto sobre circulação de mercadorias e serviços não incidirá nos serviços de "radiodifusão sonora e de sons e imagens de recepção livre e gratuita". Nos artigos 222 e 223, do Capítulo da Comunicação Social, a Constituição repete três vezes a expressão "radiodifusão sonora e de sons e imagens". 
Deste excerto extrai-se que a Constituição brasileira trata do assunto radiodifusão ora qualificando os serviços para os de rádio e televisão, ora especificando o sinal aberto e ora distinguindo-o da televisão, em uma pluralidade de termos que resulta em insegurança jurídica para as empresas que atuam no setor, pois conceitos vagos e indeterminados desestabilizam as expectativas de comportamento (MACHADO, 2002).

Ademais, convém também mencionar que a Constituição brasileira, no Capítulo V, do Título VIII, que trata da Comunicação Social, traz inúmeros termos que podem estar relacionados à radiodifusão, dentre eles os contidos no caput do artigo 220, que dispõem que a manifestação do pensamento não pode sofrer restrições em relação à "forma, processo ou veículo". No parágrafo primeiro, menciona que o "veículo de comunicação social" não pode sofrer embaraço à liberdade de informação; o parágrafo quinto determina que "os meios de comunicação social" não podem ser objeto de monopólio ou oligopólio; o artigo 221 menciona o termo "emissoras de rádio e tv"; o 222 emprega a expressão "empresa de radiodifusão"; o parágrafo terceiro do mesmo artigo trata dos "meios de comunicação social eletrônica".

Este apanhado das normas constitucionais indica uma pluralidade, indeterminação e vagueza dos termos relacionados à radiodifusão, condição que pode gerar sérias consequências em termos de segurança jurídica e de isonomia.

A despeito desta pluralidade e da indeterminação do conceito, a legislação infraconstitucional brasileira define radiodifusão como o serviço "destinado a ser recebido direta e livremente pelo público em geral, compreendendo radiodifusão sonora e televisão", art. 5., 4d, da Lei o․ 4.117/1962 (BRASIL, 1962). Trata-se de um conceito restrito que limita a sua abrangência exclusivamente para a difusão de conteúdo via espectro eletromagnético.

Esta é a compreensão da teoria e do Poder Judiciário brasileiro e aparentemente está reforçada, em âmbito legislativo, pela Lei №. 12.485/2011 conhecida como a lei do Serviço de Acesso Condicionado (SeAC) - ao excluir do campo de abrangência desta lei "os serviços de radiodifusão sonora e de sons e imagens", entendido aqui os serviços disponibilizados via espectro eletromagnético. 
Os termos da legislação, vagos, indeterminados e imprecisos, podem ser considerados entraves sérios à segurança jurídica e poderiam, em seu nome, serem declarados inconstitucionais pela insegurança que podem causar e pelo tratamento não isonômico que essa falha conceitual pode gerar.

A divergência conceitual induziu, por exemplo, a Associação Nacional de Jornais (ANJ) a ajuizar Ação Direta de Inconstitucionalidade (ADI №. 5.613) com pedido para que o Supremo Tribunal Federal dê interpretação conforme à Constituição a alguns dispositivos da Lei ㄲo. 10.610/2002, no sentido de que a expressão "empresas jornalísticas" englobe também, por exemplo, os portais de notícias veiculados pela internet.

Por sua vez, a Constituição portuguesa é mais clara e precisa. Há apenas uma menção ao termo no artigo $38^{\circ}, 7$ ao dispor que "As estações emissoras de radiodifusão e de radiotelevisão só podem funcionar mediante licença, a conferir por concurso público, nos termos da lei". Trata-se, portanto, dos serviços de radiodifusão sonora (rádio) e de sons e imagens (televisão).

A teoria portuguesa, por sua vez, alarga o conceito de radiodifusão para além do espectro eletromagnético, como será visto na seção que segue.

\section{ALGUMAS CONTRIBUIÇÕES DE TEÓRICOS PORTUGUESES}

A tese central do trabalho de Cordeiro (2004, p. 12), utilizado aqui como uma das referências da teoria portuguesa, consiste em "demonstrar que existe um conceito único de radiodifusão cuja elaboração remonta ao século passado, mas que se mantém actual e continua operativo em todas as situações" e que não há diferenças relacionadas ao suporte ou forma de transmissão pois

[...] na radiodifusão tradicional, na efectivada por cabo, por satélite ou pela Internet, normalmente designada por 'webcasting', estamos, em todas elas, perante modalidades de uma mesma realidade, havendo variações meramente quantitativas. O conceito jurídico de radiodifusão mantém-se, contudo, inalterável e operacional em qualquer dos casos. 
Neste sentido, conclui Cordeiro (2004, p. 484/485), "que existe um conceito único de radiodifusão" e que "consiste na comunicação pública de obras ou prestações através de emissões, por fio ou sem fio, destinadas a ser recebidas directamente pelo público", por fim, menciona que tanto "no âmbito tradicional, por satélite ou por cabo, ou na sua vertente digital, este é um conceito que tem valor universal".

Correia (2005, p. 38/40), por sua vez, menciona que a radiodifusão é uma espécie dos serviços "de teledifusão ou telecomunicações de uso público de difusão", sendo que a transmissão pode ser feita por "meio de ondas radioelétricas ou de qualquer outro meio apropriado".

Machado (2002, p. 601) pontua que não há um conceito de radiodifusão no texto constitucional português, no entanto, o autor enfrenta a questão dizendo que

[...] a radiodifusão compreende, genericamente, toda a comunicação dirigida a um número indeterminado de pessoas através de ondas electromagnéticas, com ou sem utilização de cabo. Nesta acepção, ela abrange a rádio e a televisão, por via hertziana terrestre, por cabo ou por satélite.

De acordo com Machado (2002, p. 602), os conceitos são forjados a partir de "aspectos arquitectónicos e estruturais relativos à emissão e à recepção, deixando para segundo plano o conteúdo". O autor exclui os serviços via internet, privilegiando os elementos arquitetônicos e estruturais no conceito e, por isso, adota um conceito mais restrito de radiodifusão, diferentemente de Cordeiro e Correia, que não fazem essa exceção, como visto.

Para Castro (2016, p. 433), o sistema regulatório português baseia-se neste aspecto, contudo, atualmente "a mesma rede ou infraestrutura pode ter diferentes finalidades, dado que o espectro, o cabo ou o satélite podem ser usados como meios de comunicação ou como meios de difusão de dados".

Continua a autora portuguesa dizendo que

A influência da regulação das telecomunicações nos conteúdos, mais precisamente na gestão do espaço liberto para a afetação dos serviços de 
programas televisivos, pode ser decisiva. Atente-se, por exemplo, na afetação de espectro, inicialmente alocados às emissões de serviços televisivos, a serviços de comunicações de outra natureza, pondo em causa a possibilidade de alargamento da oferta televisa e, por essa via, o pluralismo e a diversidade. É preciso ter em consideração, igualmente, que o futuro das redes de comunicação eletrónicas passa também pela diversificação da sua utilidade como plataformas de difusão de conteúdos, em especial no que se refere à prestação de serviços de radiodifusão televisiva e serviços audiovisuais e afins". (CASTRO, 2016, p. 433) (destaque nosso).

Prossegue Castro (2016, p. 465), afirmando que em uma época de

[...] confusão digital entre redes e conteúdos e operadores de rede, intermediários ou fornecedores da internet e os produtores de conteúdos [...] Reclama-se, por isso, a necessidade de uma opção fundamental por um modelo regulatório que se baseie no tipo de atividade efetivamente desenvolvida, ajustado à realidade digital e que saiba dar a resposta ajustada. (destaque nosso).

Na próxima seção serão apresentado aportes de diretiva europeia sobre os serviços de comunicação social audiovisual, compreendendo que esse documento adota uma definição pautada no conteúdo veiculado e não no aspecto arquitetônico estrutural do meio de transmissão.

\section{TRATAMENTO DO TEMA EM DIRETIVA EUROPEIA}

A Diretiva Europeia sobre os serviços de comunicação social audiovisual também contribui de maneira incisiva e significativa para a definição de um conceito alargado de radiodifusão, ampliando-se a sua aplicação.

No caso e, a princípio, a definição dá-se pelo conteúdo e não pelos aspectos arquitetônicos e estruturais do serviço. Neste sentido, o Considerando 27 dispõe que

A radiodifusão televisiva inclui actualmente, em particular, a televisão analógica e digital, a transmissão em directo via Internet (live streaming), a teledifusão na web e o quase vídeo a pedido, enquanto que o vídeo a pedido, por exemplo, é um serviço de comunicação social audiovisual a pedido. (Directiva, 2010/13, p. 95/4). 
O artigo $1^{\circ}$. da Directiva, alínea e, define serviços de comunicação social audiovisual, da seguinte maneira:

Radiodifusão televisiva ou emissão televisiva (ou seja, um serviço de comunicação social audiovisual linear), um serviço de comunicação social audiovisual prestado por um fornecedor de serviços de comunicação social para visionamento simultâneo de programas, ordenados com base numa grelha de programas; (Directiva, 2010/13, p. 95/12).

Por sua vez a alínea g define:

Serviço de comunicação social audiovisual a pedido (ou seja, um serviço de comunicação social audiovisual não linear), um serviço de comunicação social audiovisual prestado por um fornecedor de serviços de comunicação social para visionamento de programas pelo utilizador, a pedido individual deste, num momento por ele escolhido para o efeito com base num catálogo de programas seleccionados pelo fornecedor do serviço de comunicação social; (Directiva, 2010/13, p. 95/12)

Verifica-se, deste modo, que o conceito aparentemente está centrado no conteúdo, ou seja, no conceito de programas audiovisuais.

\section{ALGUMAS CONTRIBUIÇÕES DA TEORIA BRASILEIRA}

Dantas (2013, p. 124), em trabalho que trata dos desafios brasileiros em um cenário de mundialização midiática, ao analisar a televisão sem fronteiras na Europa, afirma que "Para as autoridades europeias, televisão, independentemente da plataforma ou modelo de negócios, permanece sendo um serviço de radiodifusão destinado a transmitir conteúdos ao público" (destaque nosso), corroborando a ideia mencionada acima de que de no acordo com a diretiva europeia, a definição de radiodifusão deve pautar-se pelo conteúdo.

Ainda analisando o plano europeu, Dantas (2013, p. 142) menciona que, de acordo com estudos elaborados naquele continente, "radiodifusão deixou de ser 
sinônimo de transmissão de programas de rádio e televisão por vias atmosféricas, abrangendo hoje em dia também a transmissão por cabo e satélite".

Dantas, durante a audiência pública realizada no Supremo Tribunal Federal, para instruir o julgamento da Ação Declaratória de Inconstitucionalidade no. 4679, que questionava dispositivos da Lei no. 12.485, afirmou que

[...] estudos e relatórios atestam que o mundo inteiro entende que televisão é ainda televisão, não importa se nas frequências VHF e UHF, como até passado recente, ou se no cabo, no satélite, em altas frequências atmosféricas, ou até em formato IPTV (via internet). (BRASIL, 2015, p. 46) (destaque no original).

O fundamento para a regulação da radiodifusão sempre foi, de acordo com Farias (2004), a escassez do espectro eletromagnético. Com as novas tecnologias, esse fundamento deixa de ter relevância, sendo que um novo embasamento regulatório precisa ser explicitado, sugerindo o autor que o seu delineamento, independentemente do suporte, deve ser

[...] como serviço público, porque este se afigura o regime jurídico mais apropriado para garantir que as emissoras de rádio e televisão possam efetivamente contribuir com a consecução dos princípios básicos que fundamentam a sociedade e o Estado brasileiros, máxime quanto à preservação da dignidade da pessoa humana, da soberania popular, da cidadania, do pluralismo político (CF, art. 1ํ, I, II, III, V), quanto a construção de uma sociedade livre, justa e solidária (CF, art. $3^{\circ}$, I) e à prevalência dos direitos humanos (CF, art. $4^{\circ}$ ). (FARIAS, 2004, p. 2018).

Em trabalho que aborda a questão do serviço e interesse público nas comunicações, Santos e Silveira (2007, p. 51) mencionam que

Os serviços de comunicações, no que se refere ao provimento de conteúdo (radiodifusão) e ao tráfego de informações (telefonia/transmissão de dados), cresceram e foram regulados sob lógicas e instâncias normativas distintas. As diferentes naturezas dos serviços fizeram com que a telefonia fosse regulada prioritariamente em relação à distribuição/transporte de informações e a radiodifusão em relação ao conteúdo. 
A dificuldade de regulação avulta-se tendo em vista a convergência dos serviços, sendo que a existência de diversas regulações pode gerar problemas jurídicos sérios (SUNDEFELD, 2004), como os apontados: insegurança jurídica e quebra na isonomia de tratamento.

Na mesma linha de raciocínio, Sankievicz (2011, p. 124) aponta que o modelo jurídico brasileiro inicialmente pensado, tendo em vista a escassez do espectro eletromagnético, encontra atualmente

[...] dificuldades para se adaptar a um mundo onde a TV a cabo, digital, por satélite, e a Internet possibilitam o aumento exponencial das possibilidades comunicativas. Hoje, a tecnologia digital possibilita a conversão de textos, sons e imagens em dígitos binários, propiciando a erosão, senão mesmo o colapso das antigas fronteiras tecnológicas e regulamentares antes existentes. As diferentes plataformas que antes eram necessárias para as várias transmissões analógicas - telefonia para voz, radiodifusão para sons e imagens, telégrafos para textos etc. - podem potencialmente ser convertidas para o mesmo código e, portanto, ser substituídas por redes digitais integradas de usos múltiplos.

Para Sankievicz (2011, p. 167), a existência dessa dualidade de regulação para o setor afronta o princípio jurídico da isonomia e por isso

[...] não haveria mais suporte para exigir da radiodifusão uma determinada disciplina jurídica, enquanto o concorrente que produz o mesmo tipo de produto estaria sujeito a regras bem mais flexíveis apenas por usar outra plataforma tecnológica.

Essa lógica na regulação foi aparentemente alterada pela Emenda Constitucional ํo. 36/2002 que, em tese, passou a regular a atividade pelo conteúdo e não pelo suporte, seguindo, assim, parte da teoria portuguesa e da normativa europeia já mencionadas, onde há preocupação acerca do que Castro (2016) mencionou ser uma anorexia constitucional, uma regulação jurídica autofágica, e até mesmo uma paralisia regulatória para o setor, não podendo "manter-se a atual dualidade hipócrita de regimes e pesos constitucionais, legitimadora de um modelo regulatório incoerente e desajustado", pois "empresas que desenvolvem precisamente a mesma atividade - conteúdos - estão sujeitas a regras e 
Reguladores diferentes, sem razões substanciais que possam justificar essa discrepância, podendo suscitar questões complexas de igualdade e concorrência" (CASTRO, 2016, p. 466). (destaque nosso)

$\mathrm{Na}$ seção que segue, apresentar-se-á a mudança de embasamento para a regulação do setor sugerida pela Emenda Constitucional nํ. 36/2002.

\section{REGULAÇÃO PELO CONTEÚDO E A EMENDA CONSTITUCIONAL №. 36}

A Emenda Constitucional №. 36, de 28 de maio de 2002, acrescentou ao artigo 222 da Constituição o parágrafo $3^{\circ}$., que dispõe que "os meios de comunicação social eletrônica, independentemente da tecnologia utilizada para a prestação do serviço, deverão observar os princípios enunciados no art. 221, na forma de lei específica, que também garantirá a prioridade de profissionais brasileiros na execução de produções nacionais". (BRASIL, 1988).

Essa alteração no texto constitucional, do ponto de vista adotado no presente trabalho, unifica as regras relativas à comunicação social, indicando que a tecnologia utilizada não pode ser considerada um entrave para a aplicação das regras do artigo 221, que determina que esses serviços devem dar preferência a finalidades educativas, artísticas, culturais e informativas, promover a cultura nacional e regional, estimular a produção independente, divulgar a produção cultural, artística e jornalística regional e, por fim, respeitar os valores éticos e sociais da pessoa e da família.

Observe-se que a Emenda Constitucional №. 36 foi proposta em 1995 e visava inicialmente ampliar a participação de pessoas jurídicas nas empresas de comunicação. O parágrafo $3^{\circ}$. somente foi incluído em abril de 2002 pelo Senado Federal, na fase final da tramitação do projeto.

A ideia de unificação da legislação fica evidente no relatório do Senador Romeu Tuma, relator designado pela Comissão de Constituição e Justiça do Senado Federal para analisar a Proposta de Emenda à Constituição. De acordo com o relator, uma nova legislação é necessária para alterar "o indesejável ambiente de 
'confusão normativa' que envolve o setor de comunicação social" e acrescenta ainda que "Em tempos de crescente convergência dos meios de transmissão e distribuição de áudio, vídeo e dados, parece evidente a necessidade do estabelecimento de mecanismos de regulação e de fiscalização que ensejem uma visão global do setor." (BRASIL, 2002, p. 4.068) (destaque nosso)

Evidentemente, que, no texto original da Constituição não havia menção expressa às novas tecnologias, bem como pelo estado da arte, em 1988, havia a diferenciação entre radiodifusão e telecomunicação, contudo, em um ambiente e em tempos de convergência tecnológica, não é razoável pensar que produtos e conteúdos idênticos sejam tratados de forma diferente apenas pelo suporte de transmissão. Neste sentido, propõe-se aqui o alargamento do conceito de radiodifusão para o de audiovisual, abarcando toda e qualquer produção de conteúdo na regulação normativa, pois não se interpretando desta forma os preceitos constitucionais/legais, haveria um claro esvaziamento dos comandos normativos.

A internet, concebida como um meio irregulamentável, não pode ficar à mercê dos interesses corporativos, neste sentido, Castro (2016, p. 92) indica que a internet "não pode ser um espaço livre de direito, integrado numa sociedade da informação, global ou transnacional", havendo a necessidade de estabelecer-se uma "Carta de Direitos para a Internet", um Bill of Rights para a comunicação digital.

$\mathrm{Na}$ seção que se segue, há aprofundamentos àss reflexões a respeito da necessidade de ampliação do conceito de radiodifusão em um percurso para além das discussões jurídicas, de forma a apresentar contribuições culturais e comunicacionais para este desafio ao Direito.

\section{DIREITO E CONVERGÊNCIA: CONTRIBUIÇÕES DA PERSPECTIVA COMUNICACIONAL}

A partir do exposto, entende-se que o direito sustenta ainda uma compreensão sobre a comunicação ligada a processos tradicionais de produção, 
transmissão e recepção de mensagens, cenário no qual há papéis cristalizados e que não se confundem. Na perspectiva de Bitelli (2004), isto ocorre devido a uma diferença entre a ciência do direito e o direito positivado, aquele que é colocado na forma da lei. Enquanto o primeiro pode olhar a sociedade e suas questões com uma visão interdisciplinar, ao direito positivo impõe-se a necessidade de traduzir o mundo em processos práticos. Com as relações comunicacionais isto não é diferente.

Além disso, há o fato de a Constituição ter sido elaborada antes do advento da comunicação digital, conforme já apontado. Assim, a realidade contemplada pela lei era analógica, constituída de relações comunicacionais em que produtores e consumidores não se confundiam, nas quais os meios tradicionais cumpriam uma mediação imprescindível ao acesso à informação.

\footnotetext{
Deve ser lembrado que a Constituição Federal de 1988 já estava pronta, acabada e vigente quando o fenômeno da convergência dos media passava a se materializar. Certamente o texto constitucional não estava, como não está, preparado para essa evolução tecnológica e, portanto, inexigível uma vocação maior para tutelar os efeitos desse acontecimento. A separação entre serviços de telecomunicações, radiodifusão e imprensa ainda foi mantida e, por consequência, o fenômeno da convergência não tem acolhida na Carta Maior. (BITELLI, 2004, p. 33).
}

No entanto, o processo de digitalização tecnológica dos meios de comunicação passa a condicionar um novo cenário cultural nas relações comunicacionais. Conceituado por Jenkins (2009), o fenômeno da convergência caracteriza-se como a tendência de consumo de conteúdos em plataformas diversas, a produção e a transmissão de mensagens que envolvam diferentes meios e o trânsito dos públicos entre as mídias diversas. Segundo o autor, a convergência não se restringe a um processo tecnológico, mas engloba uma mudança cultural nas formas de acesso à informação.

Isso posto, ao legislar sobre a comunicação, o direito passa a lidar com dois novos desafios. O primeiro, de ordem prática, diz respeito ao caráter multidisciplinar e transmídia do consumo de informações na contemporaneidade; as normas vigentes consideram os meios ainda do ponto de vista analógico, tendo como base aspectos como a limitação do espectro eletromagnético, o que não se aplica aos 
recursos digitais. Nesses casos, um mesmo dispositivo que configura uma nova forma de acesso à informação apresenta características próprias da radiodifusão, telecomunicações e audiovisual, por exemplo, áreas que tradicionalmente são regidas por leis específicas e distintas.

O segundo diz respeito ao aspecto cultural da comunicação. Nas mídias de massa, os papéis desempenhados pelos cidadãos são limitados às funções de produção e de consumo, indistinguíveis. A partir desta ótica, as leis protegem o direito à informação de quem as consome de um lado e, de outro, legisla sobre como quem produz informações deve fazê-lo, pensando na proteção daquele público.

No entanto, é necessário considerar a progressiva digitalização das relações comunicacionais por meio da expansão da internet. Segundo a pesquisa TIC Domicílios 2018, realizada pelo Comitê Gestor da Internet no Brasil e divulgada em agosto de 2019, a quantidade de residências com acesso à internet no País saltou de $18 \%$ em 2008 para $67 \%$ em 2018 . No total, $70 \%$ da população é caracterizada como usuária de internet. Esta expansão apoia-se no consumo por meio de dispositivos móveis: a pesquisa mostra que $97 \%$ dos usuários de internet utilizam-na por telefone celular, sendo que $56 \%$ tem nele a única forma de acesso.

Os dados mencionados exemplificam como a sociedade modifica-se do ponto de vista comunicacional e apontam para a necessidade de o direito encarar a comunicação não apenas como processo prático, mas enquanto dinâmica cultural em transição, como mostra o próprio conceito de convergência de Jenkins (2009).

Tendo por base o que Bitelli (2004) expressa como tendência de o direito focar na troca de informações como um processo linear, um aspecto primordial do novo cenário da comunicação é o que Lemos (2006) conceitua como "liberação do polo emissor", ou seja, no contexto digital, as fronteiras entre quem produz e quem consome informações tornam-se imprecisas. Pinheiro (2013) vai além e reflete que é justamente a desterritorialização - e consequente desmaterialização, considerando os suportes midiáticos - das relações sociais um dos principais desafios não só do direito à comunicação, mas todo o direito que passa a abranger esferas sociais agora digitalizadas. 
Os desafios jurídicos do Direito Digital incluem a quebra de paradigmas, a descentralização, a dificuldade em definir limites territoriais e físicos, a velocidade com que as decisões devem ser tomadas e a crescente capacidade de resposta dos Indivíduos. A Internet gera uma infinidade de nações virtuais - pessoas, empresas e instituições de várias partes do mundo unidas por interesses os mais variados. O grande desafio do Direito é enfrentar essa contradição entre globalização e individualização, que é a grande característica da nossa era - uma era de transição, em que convivem conceitos aparentemente tão díspares. (PINHEIRO, 2013, p. 53).

Se os dados que indicam o processo de digitalização da comunicação já mostram o quanto é necessário repensar a forma com que o direito olha para essa forma de relação social, a realidade existente em relação à garantia do que a Constituição coloca como direitos dos cidadãos a respeito da comunicação, em especial na atuação e relação com os meios de comunicação de massa, impõe esta urgência. Os desafios emergem não só na esfera da comunicação tradicional, mas também das novas mídias de comunicação digital.

À revelia das determinações constitucionais, é possível verificar que uma das questões mais sensíveis na ameaça a essa pluralidade é a concentração midiática por poucos grupos empresariais (LIMA, 2011). Tal cenário continua atual: segundo um levantamento feito em 2017 pelo Media Ownership Monitor Brasil, iniciativa da ONG Repórteres Sem Fronteiras em parceria com o Coletivo Intervozes, entre 50 veículos de comunicação analisados no País, incluindo TVs, rádios, jornais e revistas e meios digitais, nove eram propriedades do grupo Globo, cinco do grupo Bandeirantes e cinco da família Macedo (proprietária da Rede Record), considerando os três maiores grupos. Ainda dos 50 veículos, nove eram pertencentes a denominações religiosas cristãs. A consequência desta concentração é uma redução na diversidade de agentes que contribuem com a elaboração de conteúdos.

A histórica concentração do controle da mídia brasileira em mãos de poucos grupos privados restringe a concorrência, vale dizer, a pluralidade de proprietários e, consequentemente, aumenta os riscos de maior controle do comércio, isto é, de menos diversidade. Diversidade que não deve ser confundida com diferença ou segmentação mercadológica, mas diversidade na representação de distintos interesses na sociedade. (LIMA, 2011, p. 222223). 
O desafio de promover-se a diversidade também afeta a comunicação digital, mesmo em espaços nos quais os usuários têm acesso aos recursos de produção e divulgação de conteúdos, como sites de redes sociais. Outro estudo feito também pela Intervozes (2018b), que analisou a concentração midiática digital, aponta que apenas $24 \%$ dos usuários que criam conteúdos no site YouTube concentram $71 \%$ das visualizações de vídeos. No Facebook, $26 \%$ dos produtores concentram $77 \%$ do consumo.

Considerando que entre todos os usuários das plataformas citadas estão não apenas pessoas comuns, mas também empresas de comunicação, sejam elas dedicadas também a mídias tradicionais, sejam exclusivamente digitais, percebe-se que a dificuldade de promover e garantir a diversidade de conteúdos, uma das bases constitucionais mais significativas do direito à comunicação envolvendo a comunicação social, erpetua-se mesmo com o desenvolvimento e penetração das mídias digitais.

Ainda em relação aos fundamentos jurídicos que defendem o pluralismo nos meios de comunicação, há de se ressaltar dois instrumentos que corroboram com a visão de que é necessário buscar formas de garantir isso também nos meios digitais. O primeiro é a já mencionada Emenda Constitucional №. 36, segundo a qual todos os dispositivos cuja função é dotar a radiodifusão de pluralismo passariam, em tese, a valer também para a comunicação digital.

O segundo instrumento é o Marco Civil da Internet (Lei no 12.965/2014). Entre os recursos que a Lei utiliza para disciplinar os usos da rede no País e os direitos de seus usuários, estão questões como os fundamentos da liberdade de expressão, os direitos humanos, a pluralidade e a diversidade (art. $2^{\circ}$., incisos II e III), a determinação de que o acesso à internet é necessário para o exercício da cidadania (art. $7^{\circ}$.) e que cabe ao Poder Público agir para que esses objetivos em relação ao uso da internet sejam atingidos e realizados (arts. 24 a 28).

Dada a necessidade de garantir-se formas de ampliar a pluralidade dos meios de comunicação em geral e que, conforme analisam os teóricos que tratam das especificidades da comunicação digital, esta conta com o aspecto fundamental de dotar seu usuário de capacidade para não apenas consumir informações, mas 
também transmiti-las, uma proposta que se mostra válida é valorizar essa capacidade técnica que o usuário de mídias tem de expressar-se e conscientizá-lo dessa capacidade, incentivando-o também a produzir e difundir conteúdos que considere relevantes para sua realidade e de sua comunidade.

Segundo a perspectiva de Coletivo Intervozes (2018a), isso ocorreria por meio da garantia ao acesso à internet, apropriação das tecnologias de comunicação e pelo empoderamento digital dos cidadãos, processo que envolve a consciência social e comunicacional do usuário.

É preciso, entretanto, avançar e considerar o que muda em relação às
noções elaboradas em uma época em que a problemática se voltava
fundamentalmente a garantir pluralidade e diversidade nos meios de
comunicação de massa e compreender os desafios colocados para que,
hoje, os cidadãos/ãs se insiram num ambiente convergente na condição de
sujeitos e não apenas de objetos de conglomerados, governos e
tecnologias. (...) Como estratégia central para pensar a implantação do
direito à comunicação nos ecossistemas digitais, trazemos ao debate a
noção de "empoderamento digital" (...) Nosso pressuposto geral é a
afirmação da web como espaço do exercício de direitos e vivência
democrática, e não da prática do consumo, do controle por grandes agentes
(como plataformas), da concentração de mercado, da expressão cultural
vertical e homogeneizada e do debate contaminado por discursos de ódio e
bolhas ideológicas. (INTERVOZES, 2018a, p. 1-2)

Neste processo de empoderamento, o coletivo reflete que o pluralismo e a diversidade dos meios digitais são as formas de garantir a liberdade de expressão de pessoas e grupos, e que esse exercício combateria opressões e defenderia a justiça social, possibilitando a garantia de outros direitos humanos fundamentais (INTERVOZES, 2018a).

Resta clara a necessidade de aprimorar-se a forma com que se busca a garantia dos direitos e liberdades de expressão e informação dentro do contexto da comunicação digital, considerando suas características e novos efeitos nas relações sociais. Para que isso seja possível dentro das competências do direito e, considerando as tendências de produção e consumo de informações e produtos culturais nas redes, uma ampliação do conceito de radiodifusão a partir de suas finalidades de conteúdo faz-se necessária e salutar. 


\section{CONSIDERAÇÕES FINAIS}

De acordo com o exposto, verifica-se que a teoria e a legislação portuguesa, acrescidas das diretivas europeias sobre o audiovisual, podem contribuir para a definição de um conceito mais amplo de radiodifusão na legislação brasileira, ampliando-se o conceito para além do espectro eletromagnético, abarcando todo e qualquer serviço de comunicação social audiovisual, independente do suporte tecnológico.

A definição e clarificação conceitual é necessária em tempos de convergência midiática e internacionalização dos mercados, fatos que impactam a regulação local, alterando a configuração do direito interno, em regra e historicamente pautado pelos aspectos arquitetônicos e estruturais de limitação do espectro eletromagnético, e caminhando para uma regulação voltada ao conteúdo, conforme proposto pelos teóricos mencionados no texto, próxima a normativas internacionais, como foi o caso citado da diretiva europeia e de acordo com a Emenda Constitucional ํ․ 36/2002, proposta que aqui se defende.

\section{REFERÊNCIAS}

BITELLI, Marcos Alberto Sant'Anna. O Direito da Comunicação e da Comunicação Social. São Paulo: Revista dos Tribunais, 2004.

BRASIL. Lei 4117 de 27 de agosto de 1962 . Disponível em: <http://www.planalto.gov.br/ccivil_03/leis/L4117.htm>. Acesso em: 26 dez. 2019.

Lei 12965 de 23 de abril de 2014 . Disponível em <http://www.planalto.gov.br/ccivil_03/_ato2011-2014/2014/lei//12965.htm> Acesso em 27 dez. 2019.

1988. Constituição da República Federativa do Brasil de 05 de outubro de <http://www.planalto.gov.br/ccivil_03/Constituicao/Constituicao.htm>. Acesso em: 27 dez. 2019. 
<http://legis.senado.leg.br/diarios/BuscaDiario?tipDiario=1\&datDiario=11/04/2002\&pa ginaDireta=04066>. Acesso: 27 dez. 2019.

. Supremo Tribunal Federal. Ação direta de inconstitucionalidade $\mathbf{n}$. 4679, de 25 de junho de 2015. Disponível em: <http://www.stf.jus.br/arquivo/cms/noticiaNoticiaStf/anexo/ADI4679.pdf>. Acesso em 27 dez. 2019.

CASTRO, R. A. de J. G. M. B. Constituição, Lei e Regulação dos Media. Coimbra: Almedina, 2016.

CORDEIRO, P. J. F. Direito de autor e radiodifusão: um estudo sobre o direito de radiodifusão desde os primórdios até à tecnologia digital. Coimbra: Almedina, 2004.

CORREIA, L. B. Direito da comunicação social. v. 1. Coimbra: Almedina, 2005.

DANTAS, Marcos. Comunicações, desenvolvimento, democracia: desafios brasileiros no cenário da mundialização mediática. São Paulo: Fundação Perseu Abramo, 2013.

Directiva 2010/13/UE do Parlamento Europeu e do Conselho, de 10 de março de 2010. Disponível em <https://eur-lex.europa.eu/legalcontent/PT/TXT/?uri=CELEX\%3A32010L0013>. Acesso em: 27 dez. 2019.

FARIAS, E. Liberdade de expressão e comunicação: teoria e proteção constitucional. São Paulo: Revista dos Tribunais, 2004.

INTERVOZES. Direito à comunicação e internet: o empoderamento digital como garantia deste direito no ambiente online. São Paulo: Intervozes, 2018a.

Intervozes, 2018b.

Monopólios digitais: concentração e diversidade na internet. São Paulo:

JENKINS, H. Cultura da Convergência. São Paulo: Aleph, 2009.

LEMOS, A. Les trois lois de la cyberculture. Liberation de l'émission, connexion au réseau et reconfigutation culturelle. Societés, 91, p. 37-48, 2006.

LIMA, V. A. Regulação das Comunicações: história, poder e direitos. São Paulo: Paulus, 2011.

MACHADO, J. E. M. Liberdade de expressão: dimensões constitucionais da esfera pública no sistema social. Coimbra: Coimbra Editora, 2002. 
PESQUISA sobre o uso das tecnologias de informação e comunicação nos domicílios brasileiros: TIC domicílios 2018. São Paulo: Comitê Gestor da Internet no Brasil, 2019

PINHEIRO, P. P. Direito Digital. 5 ed. São Paulo: Saraiva, 2013.

PORTUGAL. Constituição da República Portuguesa de 25 de abril de 1974. Disponível em <http://www.parlamento.pt/Legislacao/Paginas/ConstituicaoRepublicaPortuguesa.as px>. Acesso em: 17 out. 2016.

REPÓRTERES sem Fronteiras. Media Ownership Monitor Brasil. 2017. Disponível em <https://brazil.mom-rsf.org/br/midia/> Acesso em: 27 dez. 2019.

SANTOS, S.; SILVEIRA, E. Serviço público e interesse público nas comunicações. In: RAMOS, M. C; S. Santos (orgs). Políticas de comunicação: buscas teóricas e práticas. São Paulo: Paulus, 2007, p. 49-82. 